\title{
A spatial Bayesian network model to assess the benefits of early warning for urban flood risk to people
}

\author{
Stefano Balbi ${ }^{1}$, Ferdinando Villa ${ }^{1,4}$, Vahid Mojtahed ${ }^{2,5}$, Karin Tessa Hegetschweiler ${ }^{3}$, and Carlo Giupponi ${ }^{2}$ \\ ${ }^{1}$ BC3, Basque Centre for Climate Change, 48940 Leioa, Spain \\ ${ }^{2}$ Ca' Foscari University of Venice, Department of Economics and Venice Centre for Climate Studies, 30123 Venice, Italy \\ ${ }^{3}$ Swiss Federal Institute for Forest, Snow and Landscape Research - WSL, 8903 Birmensdorf, Switzerland \\ ${ }^{4}$ IKERBASQUE, Basque Foundation for Science, 48013 Bilbao, Spain \\ ${ }^{5}$ Fera Science Ltd., York YO41 1LZ, UK \\ Correspondence to: Stefano Balbi (stefano.balbi@bc3research.org)
}

Received: 18 September 2015 - Published in Nat. Hazards Earth Syst. Sci. Discuss.: 29 October 2015

Revised: 14 May 2016 - Accepted: 17 May 2016 - Published: 8 June 2016

\begin{abstract}
This article presents a novel methodology to assess flood risk to people by integrating people's vulnerability and ability to cushion hazards through coping and adapting. The proposed approach extends traditional risk assessments beyond material damages; complements quantitative and semi-quantitative data with subjective and local knowledge, improving the use of commonly available information; and produces estimates of model uncertainty by providing probability distributions for all of its outputs. Flood risk to people is modeled using a spatially explicit Bayesian network model calibrated on expert opinion. Risk is assessed in terms of (1) likelihood of non-fatal physical injury, (2) likelihood of post-traumatic stress disorder and (3) likelihood of death. The study area covers the lower part of the Sihl valley (Switzerland) including the city of Zurich. The model is used to estimate the effect of improving an existing early warning system, taking into account the reliability, lead time and scope (i.e., coverage of people reached by the warning). Model results indicate that the potential benefits of an improved early warning in terms of avoided human impacts are particularly relevant in case of a major flood event.
\end{abstract}

\section{Introduction}

Fluvial flooding is the most threatening natural hazard in Europe in terms of economic impact. For instance, between 2003 and 2009, 26 major events caused market-valued damages amounting to about EUR 17 billion, with 320 human fa- talities (EEA, 2010). Flood risk management is thus a priority for the European Union (e.g., EFAS-IS, 2015; European Commission, 2007), but the quantification of the benefits of flood risk prevention measures is an unresolved challenge in disaster research, mainly because the academic community has not yet developed a shared standard to quantify flood risk. The definition and measurement of natural disaster risk are active research topics (Gain et al., 2012). The most widely adopted framework in disaster risk reduction (DRR) envisages the calculation of expected damages as a function of hazard, physical vulnerability and exposure (Crichton, 1999; UNDRO, 1980). According to the DRR framework, hazard is characterized by specific return periods - an estimate of the likelihood of the event - and together with the vulnerability it is usually expressed as a dimensionless index, while the exposure is expressed with the unit(s) of measurement of the elements at risk, in physical or monetary terms. Although disasters can impact social-ecological systems in multiple ways, this approach has been mainly used to assess damages to built infrastructure.

Ideally, as pointed out by recent literature (Balbi et al., 2013; Meyer et al., 2013), a comprehensive cost assessment should include the following cost elements:

1. damages to receptors that have a market value (direct tangible costs)

2. damages to people and the environment that have intrinsic value but no market value (direct intangible costs) 


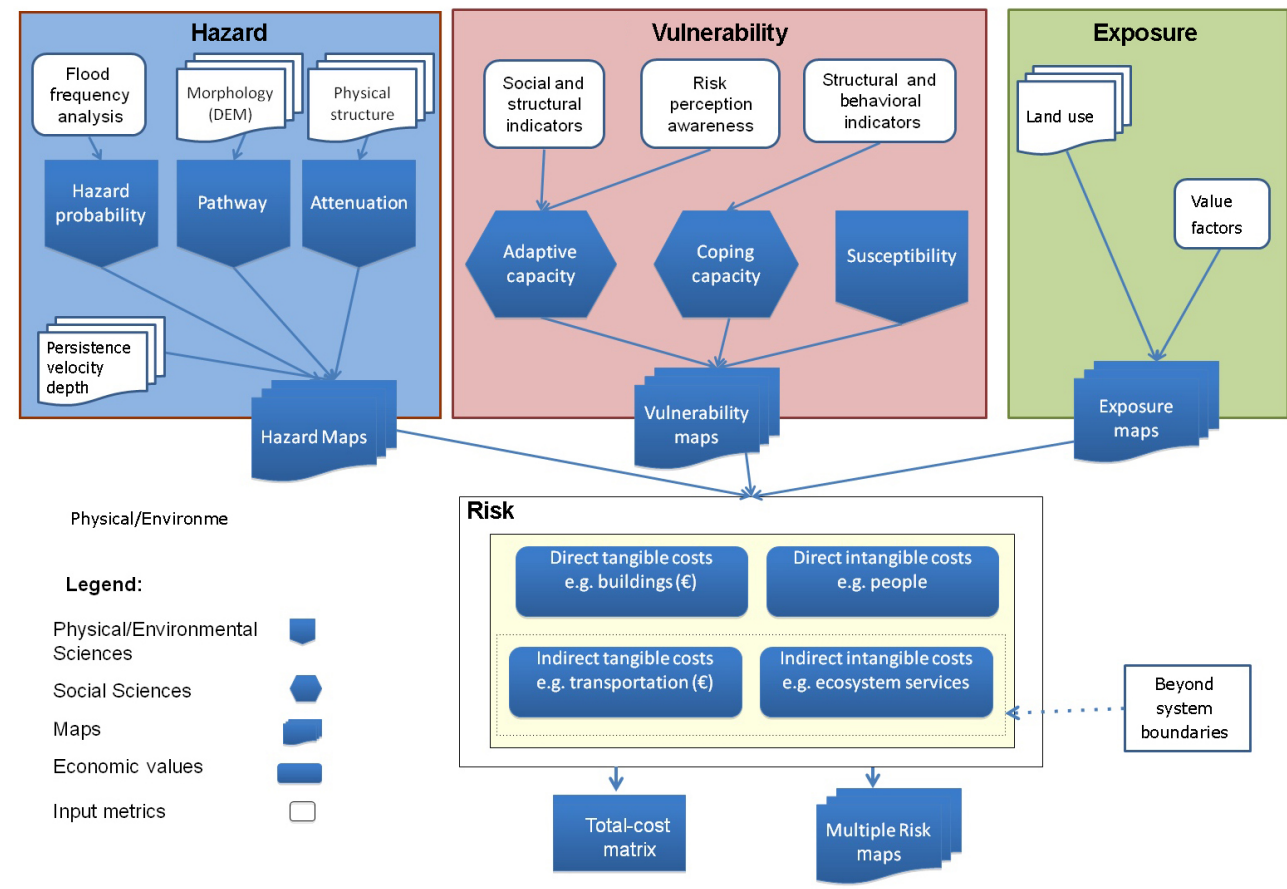

Figure 1. The KULTURisk framework with the identification of the main sources of data . Note: concept definitions are available in Giupponi et al. (2014).

3. costs generated outside the time frame or the geographical location of the hazardous event (indirect costs).

Even though a few attempts at holistic assessment exist (e,g., Jonkman et al., 2008; Gain et al., 2015), in practice only direct tangible costs are assessed most of the time (Balbi et al., 2013) because material damages are often considered sufficient to analyze and justify decisions regarding structural risk reduction measures (e.g., dikes, embankments). Another difficulty with the traditional DRR framework is that it neglects the fact that the magnitude of the costs of disasters is influenced by the adaptive behavior of communities to absorb or cushion hazards (Rose, 2004). This is evident when considering the human dimension of vulnerability (Cutter et al., 2003), which has been progressively recognized as one of the main components of risk (UNISDR, 2005). While the physical dimension of vulnerability describes the susceptibility of man-made structures and infrastructure to be negatively affected by hazardous events, the human dimension of vulnerability encompasses both the ability to cope with the hazard ex post and the capacity to adapt to hazardous events ex ante from a social perspective (Giupponi et al., 2014). During the 1990s, disaster management was primarily focused on the response of governments, communities and international organizations to deal with the consequences of disasters after they occurred. More recently, emphasis has shifted to the role of knowledge and preparedness (UNISDR, 2009) and downplaying the human dimension of vulnerability is no longer acceptable. The reason for this shift is twofold: (a) natural hazard occurrence is subject to intrinsic uncertainty, which will be exacerbated by climate change; and (b) the consequences of a natural hazard increasingly depend on the behavior of the affected communities and their capacity to adapt.

The case of early warning systems (EWSs) is iconic (Carsell et al., 2004; Nguyen et al., 2013; Daupras et al., 2015) as by anticipating the hazard they can reduce not only the amount of direct tangible costs - people can move transportable properties outside of the exposed area - but they can also (i) save human lives (direct intangible costs), (ii) change the behavior of people avoiding long-lasting trauma (indirect intangibles costs) and (iii) prevent post-disaster evacuation costs (indirect tangible costs). This article adopts the KULTURisk methodological framework (Bullo, 2013; Giupponi et al., 2014) and presents a method to quantify the benefits of EWS. The KULTURisk framework (see Fig. 1) proposes two main innovations with regards to the state of the art: (1) a non-monetary measure of risk that goes beyond direct tangible costs and (2) consideration of the individual and collective ability to reduce risk. The first is functional to the second because the quantification of intangible and indirect costs is a prerequisite for assessing the benefits of both non-structural measures and preparedness. Until recently the KULTURisk framework has been mainly implemented by means of deterministic risk assessment methods (Bullo, 2013; Mukolwe et al., 2014; Gain et al., 2015; Ronco et al., 2015), devoting only a limited attention to the treatment of uncertainty. However, uncertainty analysis and communication has a central 
role in modern flood risk management (Hall and Solomatine, 2008). In this article we propose a new variation: a probabilistic and spatially explicit model developed with Bayesian networks (BNs) based on elicited expert knowledge. We argue that this novel methodological configuration enables a more effective spatial flood risk management by differentiating risk estimates in each spatial unit of the landscape and keeping track of the associated uncertainty. We focus on flood risk to people because we assume that results can better reflect the integration of people's vulnerability and ability to cushion hazards by coping and adapting and do not need a full monetization to be clearly understood. Moreover, among the possible impacts to individuals, life loss is evidently the most relevant due to its irreversibility.

In Sect. 2, we describe the case of the greater Zurich area and the simulation scenario, the Bayesian modeling framework and the expert knowledge elicitation process. In Sect. 3 we test the sensitivity of the vulnerability module of the framework and we describe the expected flood impacts and their local implications in a spatially explicit fashion. We conclude by highlighting the importance of EWSs in the new course of integrated flood risk management, discussing the advantages and limitations of the proposed methodology and envisioning future research options.

\section{Material and methods}

\subsection{Case study: The greater Zurich area}

The case study area (see Fig. 2) is the lower part of the Sihl River valley in Switzerland. The Sihl River is a pre-alpine river with a catchment area of $336 \mathrm{~km}^{2}$ (Addor et al., 2011; Buchecker et al., 2013). Since 1938, the river discharge of the Sihl has been influenced by the Sihl Lake, a reservoir used for hydropower production located in the upper part of the river basin. The water used for energy production is not released back into the Sihl River but rather diverged into the lake of Zurich. The Sihl River valley with its sub-catchments is particularly prone to flash floods triggered by summer thunderstorms. During wintertime snow accumulates in the headwaters, melting and generating runoff into the river during the warmer months. Large parts of Zurich, Switzerland's largest city, are positioned along the alluvial cone of the river itself. The river flows through the city and runs beneath the main railway station located in the city center before joining the Limmat River (Addor et al., 2011; Buchecker et al., 2013). It has been estimated that in case of a 300- to 500-year flood event, direct tangible costs can amount up to 5 billion Swiss Francs (AWEL). In 2005, Zurich narrowly escaped a major flood when a thunderstorm moved away from Zurich towards central Switzerland. Our case study area covers an area of $78 \mathrm{~km}^{2}$ including part of the city of Zurich with 21 districts plus 5 municipalities (Adliswil, Kilchberg, Langnau am Albis, Rüschlikon, Thalwil). The residential areas cover $41.28 \mathrm{~km}^{2}$, with approximately 289000 inhabitants. About
10000 estate properties are located in hazard zones (Maidl and Buchecker, 2015).

Since 2008 the EWS IFKIS Hydro Sihl (Intercantonal Early Warning and Crisis Information System) has been in place. The system uses meteorological information, measured data from gauging stations, e.g., precipitation intensity and discharge level, and event-related information provided by observers working in the field. Models forecast the expected runoff and the information is uploaded to a visualization platform that can be accessed by all members responsible for taking decisions on flood risk control in the Sihl River basin (Romang et al., 2011). The function of the EWS is to provide decision support for local emergency response officers to consider increases in the retention capacity of the Sihl Lake. In case of an expected flood, water is preventively released from the lake (drawdown) directly into the Sihl River without passing through the power plant. The release of water increases the buffering capacity of the lake, reducing the probability of flood for the city of Zurich, but at the same time causes a decrease in power production, making false alarms costly. Moreover, in order to be effective, the release of water needs to happen at least 1 day before a serious event (Addor et al., 2011; Romang et al., 2011). Accurate forecasts within this lead time challenge current forecasting methodologies and require investments that needs to be evaluated against potential benefits (Pappenberger et al., 2015).

Despite the limitations described, the EWS is regarded as useful in significantly reducing flood risk, although its benefits have never been quantified. For the purpose of defining the EWS baseline, four experts ${ }^{1}$ from local authorities were surveyed about their perceived - thus subjective - performance of the EWS regarding its reliability (the probability of a correct forecast), lead time (time in hours between the warning and the event occurrence) and scope (the coverage of people reached by the warning). This information was collected in the form of multiple choice questions and then translated in the baseline probabilities of Table 1 using the frequency of outputs from the respondents. In this article, we consider what the implications of an alternative scenario are when the EWS is improved to its maximum effectiveness (whatever the current technology allows). This is a theoretical situation to explore the benefits of the EWS given a certain marginal change in its performances, without considering its feasibility. The assumptions about the baseline and the alternative scenario are summarized in Table 1. A different range of improvement in the EWS effectiveness spectrum may well be assessed by changing these assumptions.

\subsection{Methods: Bayesian networks to estimate risk}

Building on the traditional DRR approach (UNDRO, 1980; Crichton, 1999), our framework postulates that the magni-

\footnotetext{
${ }^{1}$ These experts are different from the 25 experts consulted to extrapolate estimated risk output (see Sect. 2.3).
} 


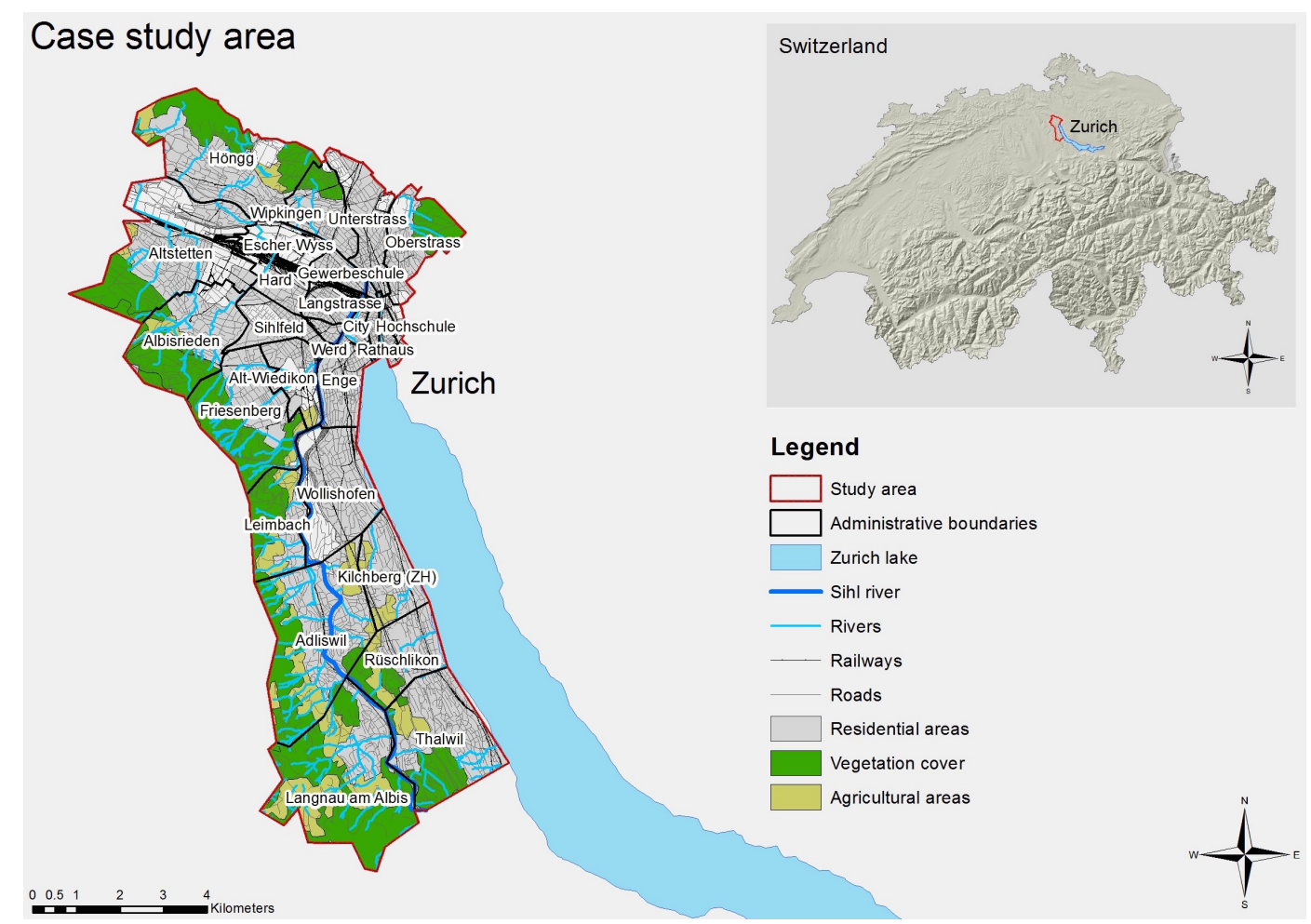

Figure 2. Case study area. Note: map produced by Martina Bullo, available in Ronco et al. (2015).

Table 1. Early warning baseline and improved scenarios. The $1 \%$ in the baseline is forced to avoid having a non-observable state in the vulnerability BN.

\begin{tabular}{l|lll|l}
\hline EWS & \multicolumn{3}{|c|}{ Baseline } & Improved \\
\hline Reliability & $1 \%^{\mathrm{a}}$ & $49 \%^{\mathrm{b}}$ & $50 \%^{\mathrm{c}}$ & $100 \%^{\mathrm{c}}$ \\
Lead time & $25 \%^{\mathrm{a}}$ & $50 \%^{\mathrm{b}}$ & $25 \%^{\mathrm{c}}$ & $100 \%^{\mathrm{c}}$ \\
Scope & $24 \%^{\mathrm{a}}$ & $75 \%^{\mathrm{b}}$ & $1 \%^{\mathrm{c}}$ & $100 \%^{\mathrm{c}}$ \\
\hline
\end{tabular}

${ }^{\mathrm{a}}$ low/insufficient; ${ }^{\mathrm{b}}$ moderate/about sufficient; ${ }^{\mathrm{c}}$ high/completely sufficient.

tude of flood risk is directly related to the intensity of the hazard as well as to the whole (i.e., physical and human) vulnerability of the exposed system. Hazard, vulnerability and exposure are integrated into a single function of risk using BNs as described in the following section.

A $\mathrm{BN}$ is a graphical representation of a joint probability distribution, which consists of a qualitative part, a directed acyclic graph representing conditional dependencies and a quantitative one, a collection of numerical parameters representing conditional probability distributions. BNs constitute a widely accepted formalism for representing uncertain knowledge (subjective or objective) and for efficiently reasoning with it (Pearl and Russell, 1998; de Campos and Castellano, 2007). In a causal network the causal influences between the considered factors are expressed with edges be- tween parent and child nodes. Each node represents a random variable defined by a probability distribution that can be continuous or discretized. The dispersion in the probability distribution of the output node (e.g., vulnerability in Fig. 4) can be considered as a proxy for model output uncertainty. BNs (both the conditional probability distributions and the structure) can be constructed through expert opinion or by learning from the data. There has been many studies in the past years on the automatic learning, so-called training (Buntine, 1996), of Bayesian networks from the data (e.g., on flood vulnerability Vogel et al., 2012) and, consequently, many learning algorithms have been developed based on different methodologies (de Campos and Castellano, 2007). In this study we employ a mixed approach whereby opinions expressed by flood experts are used to create an extended data set to train the BNs.

BNs have been applied to research problems across many disciplines, including natural resource management (McCann et al., 2006). In particular, BNs have found increasing application to environmental management under uncertainty, including integrated water management issues (e.g., Barton et al., 2008). Examples are also available in the domain of natural hazard management (Vogel et al., 2014). Amendola et al. (2000) use BNs to consider the chain of indirect damages caused by natural hazards. Antonucci et al. (2004) assess debris flow hazards using credal networks. Straub (2005) illustrates the potential of $\mathrm{BNs}$ for rockfall hazard ratings. 


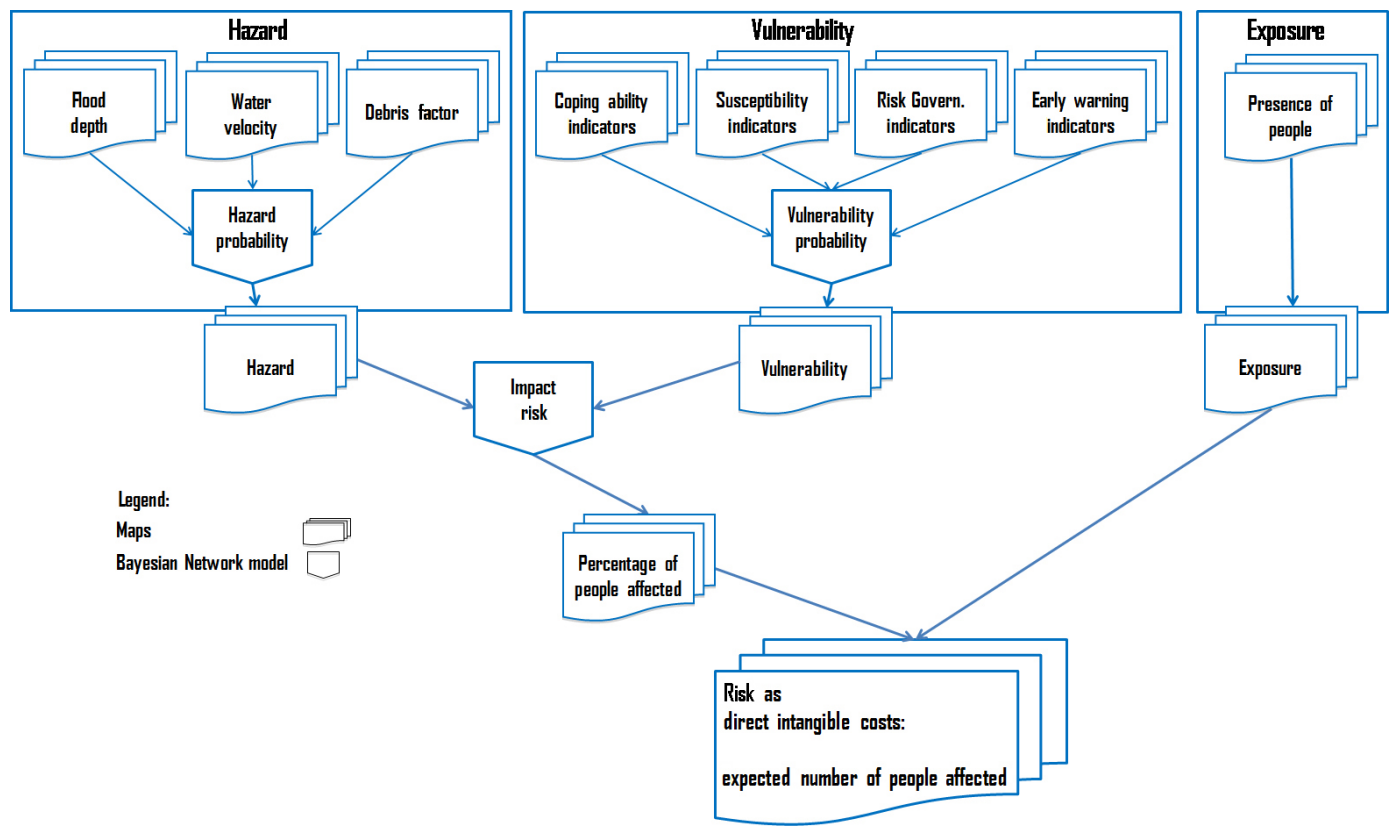

Figure 3. Customized application of the KULTURisk framework.

Vogel et al. (2012) and Schröter et al. (2014) estimate the flood damage to residential buildings using BNs trained on real world data, including usually neglected characteristics of the flooded objects, and the results outperform the traditional stage-damage function approach (Elmer et al., 2010) and keep track of uncertainty. Spatial Bayesian assessments are gaining attention from the scientific community in different disciplines, especially in epidemiology and human geography (e.g., Raso et al., 2012; Celio et al., 2014). For example, Grêt-Regamey and Straub (2006) integrate BNs with GIS to assess risk of avalanche in a spatially explicit fashion. The main advantages of BNs are the ability to mix different kinds of representation (e.g., quantitative, semi-quantitative, data-based, opinion-based), to behave correctly with missing data and to account for and help communicating uncertainties in different part of the assessments. In the case of flood risk it is common to have background knowledge about expected impacts, among which some are subjective (from experts' assessment) and some objective (from previous events). Experts possess prior information about the prevalence of possible conditions of hazard and vulnerability from previous events.

\subsection{Spatial data and Bayesian model components}

Geographical information systems and BN models are fully coupled in the simulations used for this study. The spatial context for the study is a rasterized landscape of $50 \mathrm{~m}$ resolution where models run in each grid cell. We used the GeNIe software (https://dslpitt.org/genie/wiki/GeNIe_ Documentation) to develop and test the BN modules, which were integrated and spatialized by the modeling infrastructure (see Villa et al., 2014) that directly supports GeNIe's native format ${ }^{2}$.

In Fig. 3 we show the application of the KULTURisk framework in a spatially explicit and Bayesian fashion. The hazard map, defining the level of hazard per each grid cell, is produced by the hazard $\mathrm{BN}$ feeding on three maps of flood depth, water velocity and debris factor. The vulnerability map, defining the level of vulnerability in each cell of the landscape, is produced by the vulnerability BN, thoroughly described and tested in Sect. 3. The hazard and vulnerability BN are combined into a single BN trained with the data provided by experts' opinions, as explained in the next Sect. 2.4, to produce the expected percentages of people affected by the flood. These ratios are then multiplied by the number of exposed receptors in each grid cell, provided by the exposure scenarios, to estimate the expected number of people affected. In the following we refer to each of these three modeling components in more detail ${ }^{3}$.

Hazard is commonly represented by maps of intensity of flood, provided by hydrological analysis and modeling, with reference to different return periods. For this study we used three hazard maps provided by the GIS Centre of Canton Zurich describing the flood extension of a 300-year event in terms of flood inundation depth $(D)$, velocity of flooded wa-

\footnotetext{
${ }^{2}$ The modeling infrastructure computes one inference for each object created within the simulation using the specified network developed in GeNIe; spatial models using raster data, as in this case, create one object for each cell.

${ }^{3}$ All the Bayesian modules are provided as .net files in the Supplement.
} 
ter $(V)$ and debris factor (DF). This can be considered as a worst-case scenario for the study area. The hazard Bayesian module is developed mirroring the hazard rate (HR) function of DEFRA (2006) to which we introduced stochastic noise, whereby

$\mathrm{HR}=D \times(V+\beta)+\mathrm{DF}$.

In our case we matched the combination of the discretized inputs to three levels of hazard: low hazard for HR lower than 2, moderate hazard for HR between 2 and 4 and high hazard for HR above 4 , using $\beta$ equal to 0.5 . $D$ is discretized into four states: 0 to $0.5 \mathrm{~m}, 0.5$ to $1 \mathrm{~m}, 1$ to $1.5 \mathrm{~m}$ and above $1.5 \mathrm{~m} . V$ is discretized into three states: lower than $2 \mathrm{~m} \mathrm{~s}^{-1}$, between 2 and $4 \mathrm{~m} \mathrm{~s}^{-1}$ and above $4 \mathrm{~m} \mathrm{~s}^{-1}$. DF is a binary variable, where

means absence and 1 means presence of debris factor. The mentioned discretizations are consistent with the classes derived from the equations proposed by Ronco et al. (2015) and so is the hazard map.

Vulnerability maps result from the combination of both physical and social components, as detailed in Sect. 3.1. Input variables for the vulnerability Bayesian model were broken down into four main groups of variables: coping ability, susceptibility, risk governance and early warning effectiveness. Coping ability is described by the percentage of people over 75 years old, disabled people and non-native speakers (e.g., newcomers, foreigners). The mentioned data are provided by the Statistical Offices of Canton Zurich and the City of Zurich. Susceptibility is a function of age of the exposed buildings (source: GIS Centre Canton Zurich), percentage of single and two storey buildings (source: local statistical offices) and speed of onset - the time that flood wave peak takes to reach the building, which is location dependent and derived from averages provided by the four EWS local experts for selected points within the case study area. Risk governance is articulated into societal risk awareness (derived from Maidl and Buchecker (2015) - a survey of property owners) and per capita number of emergency personnel (Hegi, Protection and Rescue Zurich, 2013, pers. communication). Early warning effectiveness is modeled as described at the end of Sect. 2.1 (see Table 1). The vulnerability BN, as the hazard $\mathrm{BN}$, matches the combinations of the discretized inputs to three levels of vulnerability: low, moderate and high.

Exposure is the presence of people and assets in the modeled landscape. In this application we employ two scenarios: (1) we use the average residential population density per district to represent human receptors in the event of an overnight flood and (2) we use data about hourly presence of people in selected public buildings of relevance (schools, stations, shopping centers, etc.) during a working day to represent human receptors in the event of a working hours flood hit ${ }^{4}$. The

\footnotetext{
${ }^{4}$ In the latter scenario, the data provided by the Civil Engineering Department of the City of Zurich cover only those districts of the study area where risks have been assessed as the highest.
}

advantage of this approach is that it offers a realistic assessment in areas with a low residential population density but high presence of people during the day, e.g., in shopping areas.

\subsection{About the use of elicited expert knowledge}

Expert knowledge has been used in three different phases of the model development:

1. a team of experts belonging to the KULTURisk Project have built and internally peer reviewed the vulnerability module (see the next section);

2. four local professionals, selected by the Swiss Federal Institute for Forest, Snow and Landscape Research (WSL) among those dealing with the EWS IFKIS Hydro Sihl, have provided the knowledge to establish the baseline conditions of the early warning effectiveness component within the vulnerability module (see Table 1);

3. 25 international flood experts, selected among authors' contacts from own institutions and from sector specific scientific conferences related to the topic (e.g., EGU Leonardo 2012: Mojtahed et al., 2012; EGU General Assembly 2013: Giupponi et al., 2013), were interviewed to extrapolate experts' estimates on risk output that were used to train the impact risk Bayesian model (see Fig. 3, i.e., the interaction of hazard and vulnerability).

In the following, we discuss the latter phase. The panel of experts was consulted through a questionnaires (provided as the Supplement) in order to deduce their opinions about expected impacts of given conditions of hazard and vulnerability within the case study. Among these experts, 20 had more than 5 years of experience on floods, 15 had been consulted by public bodies on flood risk and 10 had direct knowledge about the case study. Experts were asked to rank the likely effect on a hypothetical individual for different scenarios of hazard and vulnerability using a numeric score between 0 and 100. Both hazard and vulnerability were described as discrete states (high, moderate or low) using a narrative format. For example, moderate hazard was described through the phrase "the flood depth is marginal (e.g., $<0.5 \mathrm{~m}$ ), but the water velocity is significant for an average person (e.g., $>2 \mathrm{~m} \mathrm{~s}^{-1}$ ) and there is some debris factor"; moderate vulnerability was described as "It's a residential area of individual houses with basement, where many retired people reside. There have been flash floods before but the EWS is not at the technological level to deal with those. However, the civil protection agency is physically located within the area".

Experts provided responses about the likelihood of: (1) non-fatal physical injury, (2) post-traumatic stress disorder (PTSD) and (3) death. In the questionnaire, experts were also asked to define the effect of exposure on risk. Although 
some experts recognized the existence of a nonlinear relation, preliminary results were produced under the assumption that risk increases linearly with exposure.

The data provided by this panel of experts were aggregated to create a large representative data set. This data set was used to train the BN with bootstrap sampling, so that the contingent probabilities in the network could match the causal structure and probability distribution of the original sample. The dimension of the data set allowed the use of the PC learning algorithm, a well-established constraint learning algorithm named after its authors, Peter Spirtes and Clark Glymour (Spirtes et al., 2000). The learning process shaped a trained impact risk BN producing the three types of output in a discretized fashion. We ran this BN in each cell of a rasterized landscape, delivering probability distributions for spatially varying hazard and vulnerability factors. We finally multiplied these factors by the number of exposed receptors provided by the exposure scenarios, computing distributions for the actual number of people affected.

\section{Results and discussion}

\subsection{Analysis of the vulnerability module}

The Bayesian vulnerability module was developed and tested by the authors and experts participating to the KULTURisk consortium. The foundations of the conceptual model were established during the development of the KULTURisk framework (Mojtahed et al., 2012; Balbi et al., 2012; Giupponi et al., 2013) and are thoroughly documented in Giupponi et al. (2014). The number of factors potentially influencing vulnerability is large, and their single and joint effects are largely unknown. A minimal set of factors should include both physical and social variables (e.g, Cutter et al., 2003; Thieken et al., 2005; Adger and Vincent, 2005; Kuhlicke et al., 2011). The main challenges in assessing flood vulnerability are related to (a) tailoring the set of indicators to the context and scale and (b) aggregating and weighting indicators (or estimating the function or probability distribution from the data).

Regarding the selection of indicators, social scientists argue that vulnerability factors should be investigated in each case study by interacting with local stakeholders, mainly using semi-quantitative research approaches (e.g., Steinführer et al., 2008). We took a slightly different approach, which avoids deep stakeholder participation by making use of local knowledge from the experts involved in this study. The selection of the vulnerability indicators was tailored to the application context taking into account hazard type, spatial scale and data availability. Where the data were not spatially explicit, the available information was used to build prior probabilities for the input nodes (see Sect. 2.2). All the data were discretized for use in BNs; discretization breaks of numeric variables are either suggested by experts (e.g., speed of onset) or, lacking hypotheses on which to base discretization, uniformly distributed (e.g., age of building). Further analysis could focus on the effect of discretization (Uusitalo, 2007).

Regarding the aggregation of indicators, Giupponi et al. (2014) suggest employing a socially weighted multi-criteria method, which also implies relevant stakeholders' involvement. Coherently with the previous step, we instead opted for an expert-informed Bayesian approach, whereby preference weights are implicitly captured by the network causal structure and by the conditional probability distribution validated by the experts. Following the guidelines of Marcot et al. (2006), who detail robust strategies to develop and update untrained BNs for environmental management purposes, we represent each node of the vulnerability BN module through discrete states and then identify the single most likely outcome for each combination of parent node states, effectively forcing one outcome state for each input combination. In this development phase, we tried to approximate equal weights for each input node on the intermediate nodes, while among the intermediate nodes the effect of early warning effectiveness is doubled with respect to the others (i.e., 40 vs. $20 \%$ ). Then probabilities were adjusted to represent reasonable probability distribution. In the development of the first-cut model (named alpha-level in Marcot et al., 2006) we also respected the following principles in order to keep its complexity under control:

1. the number of parent nodes to any given node is three or fewer

2. input nodes are based on existing data (mainly spatially explicit data)

3. intermediate nodes are used to summarize the major themes (e.g., early warning effectiveness summarizes the three dimensions of EWSs).

The result of the selection and aggregation of indicators as described above is the vulnerability module represented in Fig. 4, which exhibits four main components (intermediate nodes) whereby early warning effectiveness and susceptibility include influencing factors (input nodes) typically displayed in studies of flood damages to residential buildings (Thieken et al., 2005; Merz et al., 2013), while coping ability and risk governance include typical factors of social vulnerability literature (Cutter et al., 2003; Adger and Vincent, 2005).

Sensitivity analysis shows that the results are mostly sensitive to input parameters related to risk governance. This information is detailed in Table 2, where the sensitivity of each output is broken down for every possible interval of outcome (i.e., low, moderate and high vulnerability) following the methods in Kjaerulff and van der Gaag (2000) (Sect. 4). In this analysis, based on the Tornado diagrams available in GeNIe, we consider only the effects of individual input nodes and not their combinations. A conditional confidence analysis (Christopher Frey and Patil, 2002) is performed, taking 


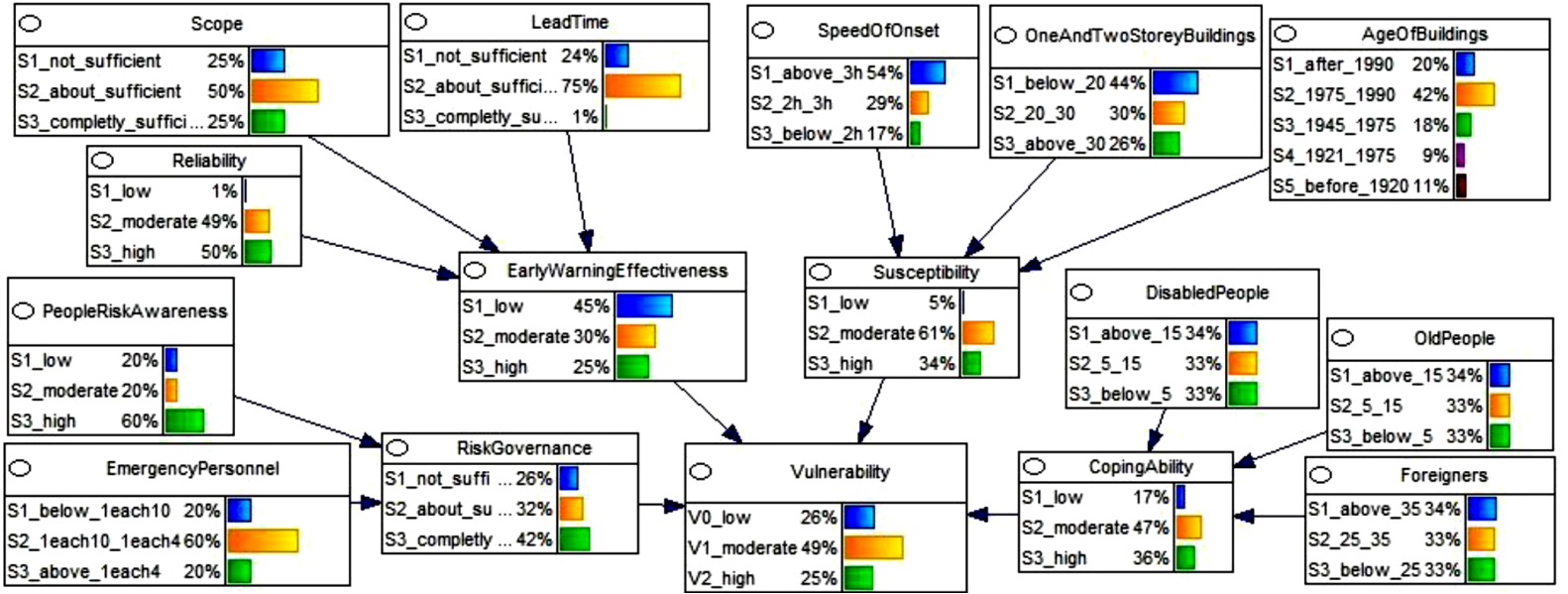

Figure 4. Vulnerability Bayesian network and summarized sensitivity.

each state of input nodes individually. For every state of the output node (i.e., vulnerability) the range of variation of the marginal probability is computed over all the possible states of the input nodes.

In Table 2, sensitive input parameters are mostly related to the emergency personnel and to the risk awareness factors. Low vulnerability is the most sensitive output state with 13 input parameter states that can induce a change in the output state probability of above $10 \%$. Among these the maximum variation $(28 \%)$ can be produced by a thorough presence of emergency personnel, which in turn increases the probability of low vulnerability. More specifically, the range effect on the target (low vulnerability) spans from 20.1 to $48.1 \%$, against a posterior probability of $25.7 \%$, and is produced with a full variation of the parameter probability, from 0 to $100 \%$.

The states of input parameters are varied to their full range for the purpose of testing this module assuming high uncertainty on the given prior probabilities. In general terms, the sensitivity of the vulnerability module is acceptable given the ranges of input change imposed. Moreover, early warning parameters do not appear to be overly sensitive to undermine the results; for example, low EWS reliability and limited EWS scope can affect the expected probability of low vulnerability up to $10-12 \%$. This is relevant in view of the discussion of results proposed in the next section.

\subsection{Simulated spatial results}

Simulated results can be presented as a comparative analysis of the baseline (i.e., presence of the current EWS) with the alternative scenario representing the improvement of the EWS to a maximum theoretical effectiveness. The latter assumes that its reliability, scope and lead time are completely effective with respect to the baseline informed by the perception of experts (See Table 1). This method allows the quantification of the expected benefits of the EWS in terms of avoided injuries, PTSD and fatalities.
The model original output are raster maps with a resolution of $50 \mathrm{~m}$. We only present a representative set of these maps (Fig. 5). For each cell in which the BN is applied the output is expressed as a discretized probability distribution. To represent uncertainty we produced maps of the coefficient of variation (CV) calculated from the distributions along with maps of the mean values in each cell. For example, Fig. $5 \mathrm{~b}$ describes the uncertainty of the probability of getting injured due to an overnight flood. An average uncertainty (CV around 0.5 ) is shown for the cells with highest expected probability, higher uncertainty is shown in some cells with low expected probability (e.g., the city) as well as in some cases of expected medium-high probability (e.g., the Werd district) as discussed in the following paragraphs. Uncertainty captures where the quality of input data could improve to produce more precise risk estimation with our model. The summary of results, aggregated per district and municipality and not taking into account the related uncertainty, is presented for the two exposure scenarios in Table 3 (day flood) and Table 4 (overnight flood). While the single scenario results in Fig. 5 communicate expected results and uncertainty per each pixel of the landscape, the summarized results in Tables 3 and 4 emphasize the changes between scenarios aggregated per district.

Our simulation suggests the importance of EWSs in reducing risk to human life for a major flood event: a very effective EWS could avoid about 153 injuries, 111 PTSDs and 3 fatalities in a day event or 266 injuries, 210 PTSDs and 14 fatalities in a night event.

The difference and spatial distributions between day and night scenarios depends on different exposure data (the two scenarios do not consider the same districts). For example, the city district could be at high risk mainly in case of day flood. Alt-Wiedikon and Langstrasse appear to be at risk in both day and overnight cases, while Albisrieden, Altstetten and Sihlfeld are mainly at risk during an overnight 
Table 2. Main sensitivities of the Bayesian vulnerability module in percentages.

\begin{tabular}{|c|c|c|c|c|c|}
\hline \multicolumn{2}{|c|}{$\begin{array}{l}\text { Low vulnerability } \\
\text { Expected prob. } \text { w/o evidence }=25.70\end{array}$} & \multicolumn{2}{|c|}{$\begin{array}{l}\text { Moderate vulnerability } \\
\text { Expected prob. } \text { w/o evidence }=49.54\end{array}$} & \multicolumn{2}{|c|}{$\begin{array}{c}\text { High vulnerability } \\
\text { Expected prob. } \text { w/o evidence }=24.76\end{array}$} \\
\hline Parameter and state & $\begin{array}{l}\text { Range effect } \\
\text { on target }\end{array}$ & Parameter and state & $\begin{array}{l}\text { Range effect } \\
\text { on target }\end{array}$ & Parameter and state & $\begin{array}{l}\text { Range effect } \\
\text { on target }\end{array}$ \\
\hline EmergencyPersonell_S3 ${ }^{\mathrm{a}}$ & $20.1-48.1^{\mathrm{a}}$ & PeopleRiskAwareness_S2 $2^{\mathrm{a}}$ & $46.4-62.1^{\mathrm{a}}$ & EmergencyPersonell_S1 ${ }^{\mathrm{a}}$ & $16.8-56.4^{\mathrm{a}}$ \\
\hline EmergencyPersonell_S1 ${ }^{\mathrm{a}}$ & $5.9-30.6^{\mathrm{a}}$ & EmergencyPersonell_S1 ${ }^{\mathrm{a}}$ & $37.7-52.5^{\mathrm{a}}$ & PeopleRiskAwareness_S1 ${ }^{\mathrm{a}}$ & $19.1-47.3^{\mathrm{a}}$ \\
\hline PeopleRiskAwareness_S3 ${ }^{\mathrm{a}}$ & $13.3-33.9^{\mathrm{a}}$ & PeopleRiskAwareness_S1 $1^{\mathrm{a}}$ & $40.2-51.8^{\mathrm{a}}$ & EmergencyPersonell_S3 $3^{\mathrm{a}}$ & $4.1-30^{\mathrm{a}}$ \\
\hline PeopleRiskAwareness_S1 ${ }^{\text {a }}$ & $12.4-29^{\mathrm{a}}$ & EmergencyPersonell_S $2^{\mathrm{a}}$ & $42.7-54.1^{\mathrm{a}}$ & PeopleRiskAwareness_S3 ${ }^{\mathrm{a}}$ & $17.6-35.4^{\mathrm{a}}$ \\
\hline PeopleRiskAwareness_S2 ${ }^{\mathrm{a}}$ & $14.3-28.5^{\mathrm{a}}$ & OldPeople_S3 ${ }^{\mathrm{c}}$ & $47.3-50.6^{\mathrm{c}}$ & AgeOfBuildings_S5 ${ }^{\mathrm{a}}$ & $23.5-35.4^{\mathrm{a}}$ \\
\hline AgeOfBuildings_S5 ${ }^{\mathrm{a}}$ & $13.9-27.1^{\mathrm{a}}$ & DisabledPeople_S $3^{c}$ & $47.3-50.6^{\mathrm{c}}$ & EmergencyPersonell_S2 ${ }^{b}$ & $21.1-30.2^{\mathrm{b}}$ \\
\hline DisabledPeople_S3 ${ }^{\mathrm{a}}$ & $21.9-33.5^{\mathrm{a}}$ & Foreigners_S3 ${ }^{\mathrm{c}}$ & $47.4-50.6^{\mathrm{c}}$ & DisabledPeople_S1 ${ }^{\mathrm{b}}$ & $21.9-30.5^{\mathrm{b}}$ \\
\hline OldPeople_S3 ${ }^{\mathrm{a}}$ & $22-33.5^{\mathrm{a}}$ & Scope_S1 ${ }^{\mathrm{c}}$ & $48.7-51.9^{\mathrm{c}}$ & Foreigners_S1 ${ }^{\mathrm{b}}$ & $22-30.3^{\mathrm{b}}$ \\
\hline Reliability_S1 ${ }^{\mathrm{a}}$ & $14.4-25.8^{\mathrm{a}}$ & Reliability_S $1^{\mathrm{c}}$ & $49.5-52.5^{\mathrm{c}}$ & Reliability_S1 ${ }^{\mathrm{b}}$ & $24.7-33^{\mathrm{b}}$ \\
\hline Foreigners_S3 $3^{\mathrm{a}}$ & $22-33.2^{\mathrm{a}}$ & Scope_S3 ${ }^{\mathrm{c}}$ & $47.3-50.2^{\mathrm{c}}$ & AgeOfBuildings_S $1^{\text {b }}$ & $18.1-26.5^{\mathrm{b}}$ \\
\hline DisabledPeople_S1 ${ }^{\mathrm{a}}$ & $18.3-29.3^{\mathrm{a}}$ & PeopleRiskAwareness_S3 ${ }^{\mathrm{c}}$ & $48.4-51.1^{\mathrm{c}}$ & DisabledPeople_S3 ${ }^{\mathrm{b}}$ & $19.1-27.5^{\mathrm{b}}$ \\
\hline Foreigners_S1 ${ }^{\mathrm{a}}$ & $18.5-29.3^{\mathrm{a}}$ & OldPeople_S1 ${ }^{\mathrm{c}}$ & $48.6-51.1^{\mathrm{c}}$ & OldPeople_S $1^{\mathrm{b}}$ & $21.8-30^{\mathrm{b}}$ \\
\hline OldPeople_S $1^{\mathrm{a}}$ & $18.7-29.5^{\mathrm{a}}$ & DisabledPeople_S1 $1^{\mathrm{c}}$ & $48.7-51.2^{\mathrm{c}}$ & OldPeople_S3 ${ }^{b}$ & $19.2-27.4^{b}$ \\
\hline Scope_S1 $1^{\mathrm{a}}$ & $17.6-28.4^{\mathrm{a}}$ & Foreigners_S $1^{\mathrm{c}^{-}}$ & $48.7-51.2^{\mathrm{c}}$ & Foreigners_S3 ${ }^{\mathrm{b}}$ & $19.4-27.4^{\mathrm{b}}$ \\
\hline AgeOfBuildings_S $1^{b}$ & $25.3-34^{\mathrm{b}}$ & EmergencyPersonell_S3 ${ }^{\mathrm{c}}$ & $47.8-50^{\mathrm{c}}$ & AgeOfBuildings_S $4^{\mathrm{b}}$ & $24.1-31.8^{\mathrm{b}}$ \\
\hline Scope_S3 ${ }^{\text {b }}$ & $23.1-33.3^{b}$ & AgeOfBuildings_S $1^{\mathrm{c}}$ & $47.8-50^{\mathrm{c}}$ & Scope_S $1^{b}$ & $22.9-30.4^{\mathrm{b}}$ \\
\hline AgeOfBuildings_S4 ${ }^{\text {b }}$ & $17.8-27.4^{\mathrm{b}}$ & LeadTime_S3 ${ }^{\mathrm{c}}$ & $47.5-49.5^{\mathrm{c}}$ & Scope_S3 ${ }^{\text {b }}$ & $19.3-26.6^{\mathrm{b}}$ \\
\hline SpeedOfOnset_S3 ${ }^{\mathrm{b}}$ & $19.4-27^{\mathrm{b}}$ & Reliability_S3 ${ }^{\mathrm{c}}$ & $48.5-50.5^{c}$ & SpeedOfOnset_S3 ${ }^{\mathrm{b}}$ & $23.6-30.2^{\mathrm{b}}$ \\
\hline OneAndTwoStoreyBuildings_S $1^{b}$ & $20.5-27.5^{b}$ & Reliability_S2 ${ }^{\mathrm{c}}$ & $48.6-50.5^{\mathrm{c}}$ & OneAndTwoStoreyBuildings_S3 ${ }^{b}$ & $23.2-29.3^{\mathrm{b}}$ \\
\hline OneAndTwoStoreyBuildings_S $1^{\text {b }}$ & $22.7-29.5^{\mathrm{b}}$ & LeadTime_S3 ${ }^{\mathrm{c}}$ & $49.2-50.5^{\mathrm{c}}$ & OneAndTwoStoreyBuildings_S $1^{\mathrm{b}}$ & $21.6-27.2^{\mathrm{b}}$ \\
\hline LeadTime_S3 ${ }^{\mathrm{b}}$ & $25.6-32.2^{\mathrm{b}}$ & AgeOfBuildings_S5 ${ }^{\mathrm{c}}$ & $49.4-50.7^{\mathrm{c}}$ & LeadTime_S3 ${ }^{\mathrm{c}}$ & $20.1-24.8^{\mathrm{b}}$ \\
\hline
\end{tabular}

Table 3. Affected human individuals per district or municipality-day flood. Note: only affected districts are shown.

\begin{tabular}{llrrrrrr}
\hline ID & $\begin{array}{l}\text { District or } \\
\text { municipality }\end{array}$ & $\begin{array}{r}\text { Injuries } \\
\text { baseline }\end{array}$ & $\begin{array}{r}\text { Injuries } \\
\text { improved }\end{array}$ & $\begin{array}{r}\text { PTSD } \\
\text { baseline }\end{array}$ & $\begin{array}{r}\text { PTSD } \\
\text { improved }\end{array}$ & $\begin{array}{r}\text { Dead } \\
\text { baseline }\end{array}$ & $\begin{array}{r}\text { Dead } \\
\text { improved }\end{array}$ \\
\hline 2 & Albisrieden & 1 & 0 & 1 & 0 & 0 & 0 \\
3 & Alt-Wiedikon & 35 & 29 & 31 & 26 & 1 & 0 \\
4 & Altstetten & 2 & 1 & 2 & 1 & 0 & 0 \\
5 & City & 486 & 358 & 428 & 337 & 2 & 1 \\
7 & Escher Wyss & 0 & 0 & 0 & 0 & 0 & 0 \\
8 & Friesenberg & 13 & 10 & 12 & 10 & 0 & 0 \\
9 & Gewerbeschule & 0 & 0 & 0 & 0 & 0 & 0 \\
12 & Höngg & 0 & 0 & 0 & 0 & 0 & 0 \\
15 & Langstrasse & 25 & 20 & 22 & 18 & 1 & 0 \\
16 & Leimbach & 3 & 2 & 3 & 2 & 0 & 0 \\
17 & Lindenhof & 0 & 0 & 0 & 0 & 0 & 0 \\
21 & Sihlfeld & 12 & 9 & 11 & 8 & 0 & 0 \\
24 & Werd & 14 & 10 & 13 & 10 & 0 & 0 \\
25 & Wipkingen & 1 & 0 & 1 & 1 & 0 & 0 \\
26 & Wollishofen & 0 & 0 & 0 & 0 & 0 & 0 \\
& Total & 592 & 439 & 524 & 413 & 4 & 1 \\
\hline
\end{tabular}

flood. The latter shows the most condensed impacts. Thalwil and Adliswil are at risk during an overnight flood, but they are not covered by exposure data for the day scenario. Enge, Hard, Hochschule, Kilchberg, Langnau am Albis, Oberstrass, Rathaus, Rüschlikon and Unterstrass are also not covered by day exposure data. Note that the effect of the EWS improvement is different in every cell and thus in every district/municipality, according to the different contribution to the reduction of vulnerability that it can achieve depending on the conditions of the other factors of vulnerability. For example, vulnerability may remain high even with a very effective EWS because susceptibility is high (due to the speed of onset) and coping capacity is particularly low (due to the presence of vulnerable human receptors). However, in this 
(a)

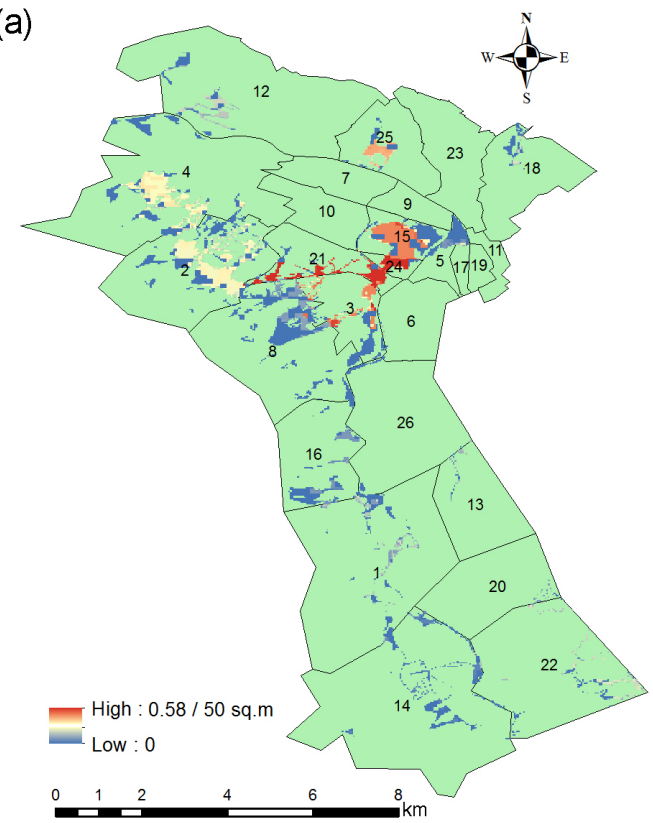

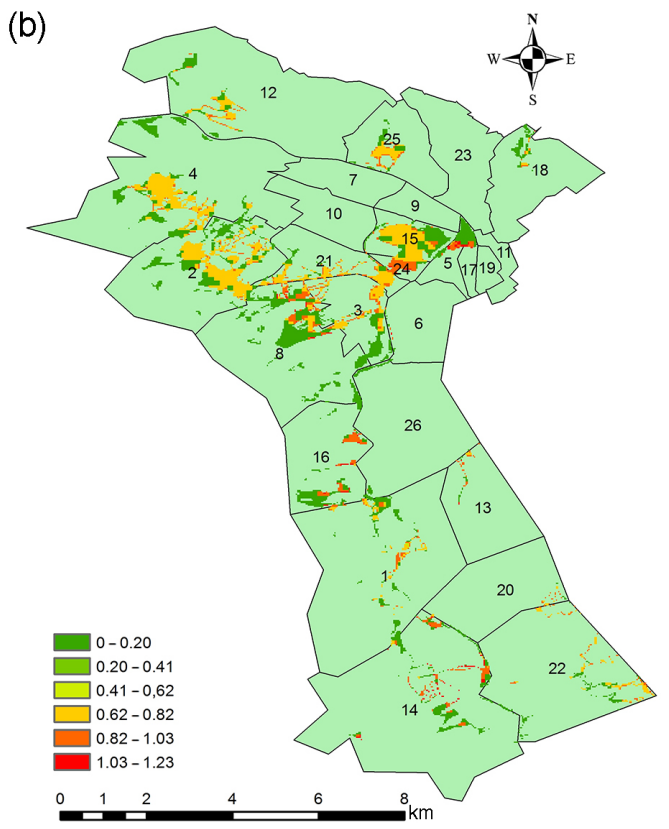

Figure 5. Spatial results describing the probability of injury in the baseline overnight flood scenario: mean (a) and coefficient of variation (b) of distribution. Note: numbering of districts refer to ID column in Table 4.

Table 4. Affected human individuals per district or municipality-overnight flood.

\begin{tabular}{|c|c|c|c|c|c|c|c|}
\hline ID & $\begin{array}{l}\text { District or } \\
\text { municipality }\end{array}$ & $\begin{array}{l}\text { Injuries } \\
\text { baseline }\end{array}$ & $\begin{array}{r}\text { Injuries } \\
\text { improved }\end{array}$ & $\begin{array}{r}\text { PTSD } \\
\text { baseline }\end{array}$ & $\begin{array}{r}\text { PTSD } \\
\text { improved }\end{array}$ & $\begin{array}{r}\text { Dead } \\
\text { baseline }\end{array}$ & $\begin{array}{r}\text { Dead } \\
\text { improved }\end{array}$ \\
\hline 1 & Adliswil & 28 & 26 & 25 & 23 & 1 & 1 \\
\hline 2 & Albisrieden & 232 & 201 & 201 & 174 & 6 & 0 \\
\hline 3 & Alt-Wiedikon & 126 & 102 & 115 & 90 & 1 & 1 \\
\hline 4 & Altstetten & 171 & 149 & 151 & 132 & 4 & 1 \\
\hline 5 & City & 7 & 3 & 6 & 3 & 1 & 0 \\
\hline 6 & Enge & 2 & 1 & 1 & 1 & 0 & 0 \\
\hline 7 & Escher Wyss & 3 & 0 & 0 & 0 & 0 & 0 \\
\hline 8 & Friesenberg & 31 & 25 & 28 & 23 & 0 & 0 \\
\hline 9 & Gewerbeschule & 0 & 0 & 0 & 0 & 0 & 0 \\
\hline 10 & Hard & 0 & 0 & 0 & 0 & 0 & 0 \\
\hline 11 & Hochschule & 0 & 0 & 0 & 0 & 0 & 0 \\
\hline 12 & Höngg & 35 & 27 & 30 & 24 & 0 & 0 \\
\hline 13 & Kilchberg & 4 & 2 & 4 & 2 & 0 & 0 \\
\hline 14 & Langnau am Albis & 8 & 6 & 7 & 5 & 1 & 0 \\
\hline 15 & Langstrasse & 231 & 195 & 201 & 172 & 1 & 0 \\
\hline 16 & Leimbach & 12 & 9 & 11 & 9 & 0 & 0 \\
\hline 17 & Lindenhof & 12 & 2 & 3 & 2 & 0 & 0 \\
\hline 18 & Oberstrass & 5 & 4 & 5 & 3 & 0 & 0 \\
\hline 19 & Rathaus & 0 & 0 & 0 & 0 & 0 & 0 \\
\hline 20 & Rüschlikon & 2 & 1 & 2 & 1 & 0 & 0 \\
\hline 21 & Sihlfeld & 266 & 192 & 231 & 173 & 2 & 1 \\
\hline 22 & Thalwil & 35 & 30 & 30 & 26 & 1 & 0 \\
\hline 23 & Unterstrass & 0 & 0 & 0 & 0 & 0 & 0 \\
\hline 24 & Werd & 86 & 66 & 76 & 63 & 0 & 0 \\
\hline 25 & Wipkingen & 67 & 56 & 59 & 50 & 0 & 0 \\
\hline \multirow[t]{2}{*}{26} & Wollishofen & 0 & 0 & 0 & 0 & 0 & 0 \\
\hline & Total & 1363 & 1097 & 1186 & 976 & 18 & 4 \\
\hline
\end{tabular}


application we do not explore how early warning effectiveness could be conditional on the timing (day vs. night) of the event.

The simulation results lead to distinguish three main types of districts that could be affected by a flood event: (1) the inner city of Zurich, (2) Zurich's nightlife district and (3) the densely populated residential areas which cover most of the case study area including the five municipalities in the Sihl valley. The city district is especially at risk during a day flood. This district is characterized by numerous commercial activities such as shops, restaurants and other businesses and includes Zurich's main railway station. It thus encapsulates the busiest areas in Zurich, although the actual number of inhabitants is relatively low. Zurich's main station is not only a central hub for national and international rail transportation but also includes an underground shopping complex with more than 130 shops and about 50 restaurants and take away services. Shops are open 365 days a year from early morning until at least $21: 00 \mathrm{~h}$ (20:00 $\mathrm{h}$ during public holidays). In addition, the main hall is used for events of all kinds, markets, shows, exhibitions, etc. The Swiss Federal Railways (SBB) estimates that about 400000 people pass through the station every day. As the Sihl River flows directly underneath the station, a flood could trap a lot of people underground. Early evacuation of the railway station is a key task to avoid major human costs in case of day flood.

In contrast to the city district, the Langstrasse district is at risk both in case of day and overnight flood. Langstrasse is a district with very mixed functions. On the one hand, it is a very popular nightlife district with plenty of restaurants, bars, pubs, discos, etc. On the other hand, it is a multicultural residential area with more than 10000 inhabitants. Rent in Langstrasse is comparatively cheap, attracting people with low incomes. The percentage of residents depending on social welfare (14\% in 2006) is the highest in Zurich. There is a high percentage of foreigners among the residents (up to $50 \%$ in certain streets), many of them with limited knowledge of German (Craviolini et al., 2008). These factors contribute to the vulnerability of the district to unusual events such as flooding. Traditionally, residents are warned by a general sound alarm and via radio about an impending flood, but especially in the Langstrasse district it might be difficult to reach everybody in this way. Jointly with Albisrieden, Altstetten, situated along the river Limmat downstream to where the Sihl joins the Limmat, is one of the residential districts most at risk in case of an overnight flood due to a relatively high population density. Measures to reduce flooding along the Limmat were implemented in 2013. A $1.8 \mathrm{~km}$ long section of the Limmat has been restored and expanded up to $8 \mathrm{~m}$, giving the river more space in case of flood events. At the same time, new dams have been constructed to protect critical areas (Zurich, 2013). In this particular case our simulation suggests that an efficient EWS could prevent most of the fatalities in case of a major overnight flood.

\section{Discussion and conclusions}

Flood risk has been traditionally measured through the expected monetary damage to material objects - mostly buildings. This may have encouraged the common practice of assessing risk reduction measures that are focused mainly on structural intervention, like dams and levees, leaving aside the influence of people's behavior in dealing with floods. Conversely, regardless of structural protections, increased exposure by means of occupation of land by human settlements has been in fact the main driver of increased flood risk in the last years (UNISDR, 2009). The evolution of land encroachment, together with the vulnerability of exposed settlements and the increasing frequency of extreme events due to climate change, is calling for a new course in integrated flood risk management.

Non-structural measures (e.g., relocation and detention basins) and preparedness (e.g., EWSs and rising risk awareness) are gaining ground in the governance of risk prevention and reduction, as words like "adaptation" and "coping ability" become of common use in the policy-making arena. In particular, EWSs are recognized as an efficient risk reduction option in flood prone areas, as flood forecasting undergoes technological innovation in terms of reliability and lead time (see Pappenberger et al., 2015). However, there are still few studies about the quantification of the benefits of EWSs. In this article we demonstrate a novel approach based on the KULTURisk framework (Balbi et al., 2012; Giupponi et al., 2014), which attempts to fill this research gap for what concerns the potential avoided consequences to human receptors.

In general, the benefits of a risk prevention measure are the difference between potential consequences determined under the baseline scenario and the potential consequences under an alternative scenario where new or improved risk prevention measures are put in place. We measure how a marginal change in the effectiveness of the EWS affects the expected impacts to human receptors. We simulate a scenario analysis focused on the potential benefits of EWS improvement to a maximum theoretical effectiveness of its performances. Even if at the moment such an improvement might not seem very realistic, it could become more accessible in the coming years thanks to the improving technology, computers, models and data collection methods. This simulation suggests that the potential benefits of a fully efficient EWS in terms of avoided human impacts are particularly relevant in case of a major flood event.

Our application tailored on the Zurich case study is proposed here as a proof of concept to explore the possible role of the combination of probabilistic methodologies, like BNs, and expert-elicited knowledge in the spatially explicit modeling of flood risk and the assessment of non-structural risk reduction measures under uncertainty. Although the delivered results appear reasonable, and are backed up by parallel studies as we discuss in the next paragraph, more research 
is required for robust policy recommendations. For example, the vulnerability model has been peer reviewed by domain experts in order to produce the final version implemented in this study. However, strategies like data learning (where data is available) or deep stakeholder inclusion (where resources are available) could be put in place for consolidating this part of the methodology. For this article we simply acknowledged these limitations and discussed a sensitivity analysis to complement the results of the vulnerability module.

Further, we only focus on risk as direct costs, whereby the human impacts in each cell of the modeled landscape take into account vulnerability, hazard and exposure of that particular cell. Thus at this stage we neglect the impacts in one cell that could be caused by the hazard and vulnerability in the neighboring cells. Additionally, we assume a linear relation between risk and exposure. However, for the more densely populated areas the probability of human impacts as provided by the experts for moderate exposure conditions may be exceeded. This may lead to underestimation of the potential risk associated with such high exposure cases. Finally, the results and the related uncertainty could change if a different set of experts were consulted.

The results of our simulation reinforce that, from a methodological point of view, it is possible to employ quantitative data (flood modeling and GIS data), and semiquantitative information integrating subjective (expert opinion) and local knowledge (risk perception and EWS baseline), to produce estimates in line with more established (and deterministic) approaches. In particular, the application of BNs allows us to produce probabilistic results and include an explicit visualization of model uncertainty. Moreover, the incorporation of early warning scenarios allows the assessment of the potential benefits of the EWS.

As a mean of preliminary cross-validation, we can anticipate that the results for the baseline overnight flood scenario, for what concerns injuries and fatalities, are dimensionally and spatially consistent with the equivalent GIS analysis carried out during the KULTURisk project with a deterministic model and no expert involvement (Bullo, 2013; Olschewski, 2013; Ronco et al., 2015). The probabilistic and expertinformed results reflect a more pessimistic outlook on injuries (1300 vs. 1000 people affected) and appear slightly more conservative about fatalities (18 vs. 29 deaths). Compared to the mentioned deterministic application the main advantage of using a probabilistic methodology like BNs is the possibility of using the information on uncertainty, deriving from both model structure and data, as showed in Fig. 5b. The communication of uncertainty is an added value of this methodology because it improves the transparency and reliability of the results. In addition, having the vulnerable part of the framework developed in Bayesian fashion allows us to analyze hypothetical scenarios that have been difficult to capture in the past such as in the case of EWS. By altering baseline conditions of key variables related to early warning effectiveness, we are able to simulate ex ante the benefits of im- proving the business as usual conditions. The quantification of the required investments are beyond the scope of this paper although a local planner could get an idea of the hotspots where to intervene both in terms of expected impacts and uncertainty level: for example, a decision to be taken in an area where high uncertainty should drive research to improve the quality of the data that feed into the model or the model itself if the goodness of data is considered to be satisfactory. Finally, with respect to the original application of the KULTURisk methodology, our model also considers an alternative scenario of EWS improvement both for overnight and day flood.

This work could be further expanded in two main ways. The simplest one is the comparison of the costs and the benefits of the EWS. This comparison requires the estimation of investments and running costs related to a fully efficient EWS, as envisioned in our scenario, including the state of the art forecasting models, real time weather data assimilation, full population warning coverage, personnel requirements for operation and maintenance, etc. Such a development would in turn lead to the monetization of the benefits, differently from what we presented in the results section. Under a more traditional economic perspective, it is possible to envisage ways to estimate monetary values by applying the method of disability-adjusted life years (DALY) (Murray et al., 2013) to injuries and PTSD results and to assess the loss of lives using the value of statistical life (VSL) method (Jonkman et al., 2003). While DALY quantifies the burden of being in states of poor health or disability (including the implications of age on productivity) in terms of forgone good years of expected life, VSL captures the value that an individual places on a marginal change in their likelihood of death. Bearing in mind the widespread criticism around these two methods (mainly for VSL), monetized figures can later fit into a traditional cost-benefit analysis framework. More interestingly, greater innovation could derive from the hazard modeling part of the approach described in this article. While we presented a static hazard scenario provided by exogenous hydrological models, we also envision the possibility to integrate a flood module, which would be able to simulate different hazards linked to a weather generator module. This would sustain the ability to test different climate change scenarios. Further technological developments are focusing on the automated generation of questionnaires from the BN structure and the use of eparticipation methodologies (Bojovic et al., 2015) to extract BNs training data.

\section{The Supplement related to this article is available online at doi:10.5194/nhess-16-1323-2016-supplement.}

Author contributions. S. Balbi prepared the manuscript with contributions from all co-authors. S. Balbi, V. Mojtahed and C. Giupponi developed the conceptual model and the individual Bayesian 
modules. K. T. Hegetschweiler collected the data and coordinated with local experts. S. Balbi and F. Villa trained the Bayesian modules, implemented the model into code and carried out the sensitivity analysis. S. Balbi developed the questionnaire and with T. K. Hegetschweiler managed interviews and responses.

Acknowledgements. This research was partially funded by the KULTURisk (Knowledge-based approach to develop a cULTURE of Risk prevention) project, FP7-ENV-2010|Project 265280 (www.kulturisk.eu). The authors want to thank the 25 flood risk experts and the four EWS experts interviewed. We express our gratitude to Roland Olschewski and Matthias Buchecker (Swiss Federal Institute for Forest, Snow and Landscape Research WSL) and Martina Bullo (Department of Environmental Sciences, Informatics and Statistics, Ca' Foscari University of Venice) for the insights provided by their work. Special thanks to Animesh Gain and Claudio Biscaro (Department of Economics, Ca' Foscari University of Venice) for the review of the vulnerability module. We also want to acknowledge Valentina Gallina, Silvia Torresan, Elena Semenzin and Alex Zabeo (Department of Environmental Sciences, Informatics and Statistics, Ca' Foscari University of Venice) for the contribution in the development of the KULTURisk Framework. The technology used to integrate BNs with GIS is k.LAB http://aries.integratedmodelling.org/, a semantic meta-modeling platform developed by co-author Villa (Villa et al., 2014). The BN modules were developed and tested with the GeNIe software https://dslpitt.org/genie/wiki/GeNIe_Documentation. The GIS results have been elaborated with the QGIS open source application www.qgis.org.

Edited by: H. Kreibich

Reviewed by: two anonymous referees

\section{References}

Addor, N., Jaun, S., Fundel, F., and Zappa, M.: An operational hydrological ensemble prediction system for the city of Zurich (Switzerland): skill, case studies and scenarios, Hydrol. Earth Syst. Sci., 15, 2327-2347, doi:10.5194/hess-15-23272011, 2011.

Adger, W. N. and Vincent, K.: Uncertainty in adaptive capacity, C. R. Geosci., 337, 399-410, 2005.

Amendola, A., Ermoliev, Y., Ermolieva, T. Y., Gitis, V., Koff, G., and Linnerooth-Bayer, J.: A systems approach to modeling catastrophic risk and insurability, Nat. Hazards, 21, 381-393, 2000.

Antonucci, A., Salvetti, A., and Zaffalon, M.: Hazard assessment of debris flows by credal networks, in: iEMSs, 98-103, 2004.

AWEL: Amt für Abfall, Wasser, Energie und Luft: Hochwasserschutz an Sihl, Zürichsee und Limmat: Integrales Risikomanagement und Massnahmenziel-Konzept, available at: http:// www.hochwasserschutz-zuerich.zh.ch (last access: 7 June 2016), 2013.

Balbi, S., Giupponi, C., Gain, A., Mojtahed, V., Gallina, V., Torresan, S., and Marcomini, A.: A Conceptual Framework for Comprehensive Assessment of Risk Prevention Measures: The Kulturisk Framework (KR-FWK), Available at SSRN 2184193, 2012.
Balbi, S., Giupponi, C., Olschewski, R., and Mojtahed, V.: The economics of hydro-meteorological disasters: approaching the estimation of the total costs, BC3 Working Paper Series 2013-12, 2013.

Barton, D., Saloranta, T., Moe, S., Eggestad, H., and Kuikka, S.: Bayesian belief networks as a meta-modelling tool in integrated river basin managementóPros and cons in evaluating nutrient abatement decisions under uncertainty in a Norwegian river basin, Ecol. Econ., 66, 91-104, 2008.

Bojovic, D., Bonzanigo, L., Giupponi, C., and Maziotis, A.: Online participation in climate change adaptation: A case study of agricultural adaptation measures in Northern Italy, J. Environ. Manage., 157, 8-19, 2015.

Buchecker, M., Salvini, G., Di Baldassarre, G., Semenzin, E., Maidl, E., and Marcomini, A.: The role of risk perception in making flood risk management more effective, Nat. Hazards Earth Syst. Sci., 13, 3013-3030, doi:10.5194/nhess-13-30132013, 2013.

Bullo, M.: Flood risk: Application and validation of a regional risk assessment methodology to the case study of Sihl river in Zurich, Masters thesis, Ca'Foscari University of Venice, Venice, Italy, 2013.

Buntine, W.: A guide to the literature on learning probabilistic networks from data, IEEE T. Knowl. Data En., 8, 195-210, 1996.

Carsell, K. M., Pingel, N. D., and Ford, D. T.: Quantifying the benefit of a flood warning system, Nat. Hazards Review, 5, 131-140, 2004.

Celio, E., Koellner, T., and Grêt-Regamey, A.: Modeling land use decisions with Bayesian networks: Spatially explicit analysis of driving forces on land use change, Environ. Modell. Softw., 52, 222-233, 2014.

Christopher Frey, H. and Patil, S. R.: Identification and review of sensitivity analysis methods, Risk Anal., 22, 553-578, 2002.

Craviolini, C., Heye, C., and André, O.: Das Langstrassenquartier. Veränderungen, Einflüsse, Einschätzungen - 1990 bis 2007, Zürich: Stadt Zürich, 2008.

Crichton, D.: The risk triangle, Natural disaster management, Tudor Rose, London, UK, 102-103, 1999.

Cutter, S. L., Boruff, B. J., and Shirley, W. L.: Social vulnerability to environmental hazards, Soc. Sci. Quart., 84, 242-261, 2003.

Daupras, F., Antoine, J., Becerra, S., and Peltier, A.: Analysis of the robustness of the French flood warning system: a study based on the 2009 flood of the Garonne River, Nat. Hazards, 75, 215-241, 2015.

de Campos, L. M. and Castellano, J. G.: Bayesian network learning algorithms using structural restrictions, Int. J. Approx. Reason., 45, 233-254, 2007.

DEFRA: Flood Risk to people Phase 2, FD2321-TR2 Guidance Document March 2006, Tech. rep., Department for Environment, Food \& Rural Affairs, London, UK, 2006.

EEA: Mapping the Impacts of Natural Hazards and Technological Accidents in Europe: An Overview of the Last Decade, European Environment Agency, Copenhagen, Denmark, 2010.

EFAS-IS: European Flood Awareness System, available at: http:// efas.eu/, last access: 11 November 2015.

Elmer, F., Thieken, A. H., Pech, I., and Kreibich, H.: Influence of flood frequency on residential building losses, Nat. Hazards Earth Syst. Sci., 10, 2145-2159, doi:10.5194/nhess-10-21452010, 2010. 
European Commission: Directive 2007/60/EC of the European Parliament and of the Council of 23 October 2007 on the assessment and management of flood risks, 2007.

Gain, A. K., Mojtahed, V., Biscaro, C., Balbi, S., and Giupponi, C.: An integrated approach of flood risk assessment in the eastern part of Dhaka City, Nat. Hazards, 79, 1499-1530, 2015.

Gain, A. K., Giupponi, C., and Renaud, F. G.: Climate change adaptation and vulnerability assessment of water resources systems in developing countries: A generalized framework and a feasibility study in Bangladesh, Water, 4, 345-366, 2012.

Giupponi, C., Gain, A., Mojtahed, V., and Balbi, S.: The socioeconomic dimension of flood risk assessment: insights of KULTURisk framework, in: EGU General Assembly Conference Abstracts, vol. 15, p. 2456, 2013.

Giupponi, C., Mojtahed, V., Gain, A. K., Biscaro, C., and Balbi, S.: Integrated risk assessment of water related disasters, Paron, P. and Di Baldassarre, G., Hydro-Meteorological Hazards, Risks, and Disasters, Elsevier, 163-200, 2014.

Grêt-Regamey, A. and Straub, D.: Spatially explicit avalanche risk assessment linking Bayesian networks to a GIS, Nat. Hazards Earth Syst. Sci., 6, 911-926, doi:10.5194/nhess-6-911-2006, 2006.

Hall, J. and Solomatine, D.: A framework for uncertainty analysis in flood risk management decisions, International Journal of River Basin Management, 6, 85-98, 2008.

Jonkman, S., Van Gelder, P., and Vrijling, J.: An overview of quantitative risk measures for loss of life and economic damage, J. Hazard. Mater., 99, 1-30, 2003.

Jonkman, S., Bočkarjova, M., Kok, M., and Bernardini, P.: Integrated hydrodynamic and economic modelling of flood damage in the Netherlands, Ecol. Econ., 66, 77-90, 2008.

Kjaerulff, U. and van der Gaag, L. C.: Making sensitivity analysis computationally efficient, in: Proceedings of the Sixteenth conference on Uncertainty in artificial intelligence, Morgan Kaufmann Publishers Inc., San Francisco, CA, USA, 317-325, 2000.

Kuhlicke, C., Scolobig, A., Tapsell, S., Steinführer, A., and De Marchi, B.: Contextualizing social vulnerability: findings from case studies across Europe, Nat. Hazards, 58, 789-810, 2011.

Maidl, E. and Buchecker, M.: Raising risk preparedness by flood risk communication, Nat. Hazards Earth Syst. Sci., 15, 15771595, doi:10.5194/nhess-15-1577-2015, 2015.

Marcot, B. G., Steventon, J. D., Sutherland, G. D., and McCann, R. K.: Guidelines for developing and updating Bayesian belief networks applied to ecological modeling and conservation, Can. J. Forest Res., 36, 3063-3074, 2006.

McCann, R. K., Marcot, B. G., and Ellis, R.: Bayesian belief networks: applications in ecology and natural resource management, Can. J. Forest Res., 36, 3053-3062, 2006.

Merz, B., Kreibich, H., and Lall, U.: Multi-variate flood damage assessment: a tree-based data-mining approach, Nat. Hazards Earth Syst. Sci., 13, 53-64, doi:10.5194/nhess-13-53-2013, 2013.

Meyer, V., Becker, N., Markantonis, V., Schwarze, R., van den Bergh, J. C. J. M., Bouwer, L. M., Bubeck, P., Ciavola, P., Genovese, E., Green, C., Hallegatte, S., Kreibich, H., Lequeux, Q., Logar, I., Papyrakis, E., Pfurtscheller, C., Poussin, J., Przyluski, V., Thieken, A. H., and Viavattene, C.: Review article: Assessing the costs of natural hazards - state of the art and knowledge gaps, Nat. Hazards Earth Syst. Sci., 13, 1351-1373, doi:10.5194/nhess-13-1351-2013, 2013.

Mojtahed, V., Balbi, S., and Giupponi, C.: Flood Risk Assessment through Bayesian Networks: Effects of Adaptive and Coping Capacity in Risk Reduction to People, in: EGU Leonardo Conference, 2012.

Mukolwe, M., Di Baldassarre, G., and Bogaard, T.: KULTURisk Methodology Application: Ubaye Valley (Barcelonnette, France), Hydro-Meteorological Hazards, Risks, and Disasters, Elsevier, p. 201, 2014.

Murray, C. J., Vos, T., Lozano, R., Naghavi, M., Flaxman, A. D., Michaud, C., Ezzati, M., Shibuya, K., Salomon, J. A., Abdalla, S., et al.: Disability-adjusted life years (DALYs) for 291 diseases and injuries in 21 regions, 1990-2010: a systematic analysis for the Global Burden of Disease Study 2010, Lancet, 380, $2197-$ 2223, 2013.

Nguyen, T. C., Robinson, J., Kaneko, S., and Komatsu, S.: Estimating the value of economic benefits associated with adaptation to climate change in a developing country: A case study of improvements in tropical cyclone warning services, Ecol. Econ., 86, 117-128, 2013.

Olschewski, R.: Sihl/Zurich case study, The 3rd KULTURisk workshop: Benefits of disaster prevention measures: consolidating and widening an innovative risk assessment methodology, available at: http://www.corila.it/?q=node/180 (last access: 7 June 2016) 2013.

Pappenberger, F., Cloke, H. L., Parker, D. J., Wetterhall, F., Richardson, D. S., and Thielen, J.: The monetary benefit of early flood warnings in Europe, Environ. Sci. Policy, 51, 278-291, 2015.

Pearl, J. and Russell, S.: Bayesian networks, Computer Science Department, University of California, Los Angeles, CA, USA, 1998.

Raso, G., Schur, N., Utzinger, J., Koudou, B. G., Tchicaya, E. S., Rohner, F., NíGoran, E. K., Silué, K. D., Matthys, B., Assi, S., and Tanner, M.: Mapping malaria risk among children in Côte dílvoire using Bayesian geo-statistical models, Malaria J., 11, 160, 2012.

Romang, H., Zappa, M., Hilker, N., Gerber, M., Dufour, F., Frede, V., Bérod, D., Oplatka, M., Hegg, C., and Rhyner, J.: IFKISHydro: an early warning and information system for floods and debris flows, Nat. Hazards, 56, 509-527, 2011.

Ronco, P., Bullo, M., Torresan, S., Critto, A., Olschewski, R., Zappa, M., and Marcomini, A.: KULTURisk regional risk assessment methodology for water-related natural hazards - Part 2: Application to the Zurich case study, Hydrol. Earth Syst. Sci., 19, 1561-1576, doi:10.5194/hess-19-1561-2015, 2015.

Rose, A.: Economic principles, issues, and research priorities in hazard loss estimation, in: Modeling spatial and economic impacts of disasters, pp. 13-36, Springer, New York, USA, 2004.

Schröter, K., Kreibich, H., Vogel, K., Riggelsen, C., Scherbaum, F., and Merz, B.: How useful are complex flood damage models?, Water Resour. Res., 50, 3378-3395, 2014.

Spirtes, P., Glymour, C. N., and Scheines, R.: Causation, prediction, and search, vol. 81, MIT press, Cambridge, MA, USA and London, UK, 543 pp., 2000.

Steinführer, A., Kuhlicke, C., De Marchi, B., Scolobig, A., Tapsell, S., and Tunstall, S.: Towards flood risk management with the people at risk: From scientific analysis to practice recommendations (and back), Flood Risk Management: Research and Prac- 
tice: Extended Abstracts Volume (332 pp.)+ full paper CD-ROM, p. $167,2008$.

Straub, D.: Natural hazards risk assessment using Bayesian networks, in: 9th International Conference on Structural Safety and Reliability, 19-23 June 2005, Rome, Italy, 20-23, 2005.

Thieken, A. H., Müller, M., Kreibich, H., and Merz, B.: Flood damage and influencing factors: New insights from the $\mathrm{Au}-$ gust 2002 flood in Germany, Water Resour. Res., 41, W12430, doi:10.1029/2005WR004177, 2005.

UNDRO: Natural Disasters and Vulnerability Analysis, Tech. rep., United Nations Disaster Relief Organization, Geneve, Switzerland, 1980.

UNISDR: Hyogo framework for action 2005-2015: Building the resilience of nations and communities to disasters, United Nations International Strategy for Disaster Reduction, Geneve, Switzerland, 2005.

UNISDR: Global assessment report on disaster risk reduction - risk and poverty in a changing climate, United Nation International Strategy for Disaster Reduction, Geneve, Switzerland, 2009.
Uusitalo, L.: Advantages and challenges of Bayesian networks in environmental modelling, Ecol. Model., 203, 312-318, 2007.

Villa, F., Bagstad, K. J., Voigt, B., Johnson, G. W., Portela, R., Honzak, M., and Batker, D.: A methodology for adaptable and robust ecosystem services assessment, PloS one, 9, e91001, doi:10.1371/journal.pone.0091001, 2014.

Vogel, K., Riggelsen, C., Merz, B., Kreibich, H., and Scherbaum, F.: Flood damage and influencing factors: a Bayesian network perspective, in: 6th European Workshop on Probabilistic Graphical Models (PGM 2012), University of Granada, Granada, Spain, 2012.

Vogel, K., Riggelsen, C., Korup, O., and Scherbaum, F.: Bayesian network learning for natural hazard analyses, Nat. Hazards Earth Syst. Sci., 14, 2605-2626, doi:10.5194/nhess-14-26052014, 2014.

Zurich, B. D. C.: Limmatauen Werdhölzli: Abschluss eines Vorzeigeprojekts, available at: http://www.zh.ch/internet/ de/aktuell/news/medienmitteilungen/2013/209_limmatauen. html (last access: 7 June 2016), 2013. 